\title{
Nuevos desafíos para la equidad en Uruguay
}

\section{Rubén Kaztman}

Director del Programa

de Investigación

sobre Integración Social,

Pobreza y Exclusión,

Universidad Católica

de Uruguay

Kaztman@adinet.com.uy

\section{Fernando Filgueira}

Doctor en Ciencias Políticas

e Investigador en el

mismo programa

filgue@chasque.apc.org

\section{Magdalena Furtado}

Economista

Oficina de la CEPAL

en Montevideo

cepal@adinet.com.uy
Desde las primeras décadas del siglo XX Uruguay presentó niveles de equidad y de desarrollo de sus instituciones de bienestar social que le permitieron descollar en el entorno latinoamericano. En la segunda mitad del siglo, esa herencia de democracia y equidad sobrevivió sin demasiadas fisuras a las duras pruebas a la que fue sometida. Una prueba consistente de la fortaleza de la matriz sociocultural del país fue su capacidad para mantener, una vez recuperada la democracia en 1985, la posición de liderazgo que tradicionalmente ocupó en la región en cuanto a desarrollo social, y que en esta oportunidad se reflejó en índices de pobreza y de desigualdad en la distribución del ingreso inferiores a los de otras naciones latinoamericanas. Los autores sostienen que en los últimos quince años del siglo XX el Uruguay logró procesar esos desafíos manteniendo un adecuado balance entre los aspectos políticos, sociales y económicos del desarrollo. El tema se analiza mediante la presentación de la posición de Uruguay en el escenario latinoamericano. Utilizando el mismo tipo de indicadores, se describe luego la evolución del país en los últimos quince años del siglo XX. Enseguida se discuten algunos de los procesos más importantes que, en el mercado, en los hogares y en el Estado, subyacen a esas tendencias. Y por último se presentan algunas reflexiones sobre los principales desafíos que deberá enfrentar el país para preservar o mejorar el nivel ya alcanzado de integración nacional sobre bases de equidad. 


\section{I}

\section{Introducción}

Si bien se trata de un fenómeno generalizado, la reestructuración económica que acompaña a la globalización no ocurre en un vacío social y político. Por el contrario, ella tiene lugar en sociedades que presentan una amplia variedad de regímenes regulatorios, estructuras institucionales, marcos jurídicos y sistemas de bienestar, que condensan los rasgos más importantes de sus matrices socioculturales. Por lo tanto, aunque los procesos asociados al estilo que orienta los actuales modelos de desarrollo se dan en la mayoría de los países, el ritmo, la secuencia y el contenido de las reformas $\mathrm{y}$, por ende, sus consecuencias sociales, son diferentes.

Desde las primeras décadas del siglo XX Uruguay presentó niveles de equidad y de desarrollo de sus instituciones de bienestar social que le permitieron descollar en el entorno latinoamericano. La ausencia de divisiones étnico-culturales significativas, los importantes excedentes de la producción primaria y una temprana consolidación democrática fueron algunos de los factores que contribuyeron a establecer la matriz sociocultural que dio lugar a esa destacada posición relativa.

En la segunda mitad del siglo, esa herencia de democracia y equidad sobrevivió sin demasiadas fisuras a las duras pruebas a que fue sometida: un estancamiento económico prolongado, conflictos entre orientaciones radicalmente distintas sobre la organización de la sociedad y de la economía — que en su momento pusieron en jaque la estabilidad política- y un golpe de Estado que instauró un gobierno militar. Prueba de la fortaleza de la matriz sociocultural del país fue su capacidad para mantener, una vez recuperada la democracia en 1985, la posición de liderazgo que tradicionalmente ocupó en la región en cuanto a desarrollo social, y que en esa oportunidad se reflejó en índices de pobreza y de desigualdad en la distribución del ingreso inferiores a los de otras naciones latinoamericanas.

Sin duda el retorno a la democracia generó condiciones favorables para preservar esa herencia de equidad, así como para enfrentar los nuevos retos que amenazaban su mantenimiento. Las principales amenazas se vinculaban a las consecuencias, diferentes sobre distintos segmentos de la sociedad, de la incorporación al mundo globalizado, de la ampliación de la frontera de la competitividad y de la adecuación del funcionamiento de las instituciones de bienestar a las exigencias de un crecimiento sostenido dentro de los nuevos parámetros.

En esta sección se postula que, en los últimos quince años del siglo XX, el país logró enfrentar esos desafíos, manteniendo un adecuado equilibrio entre los aspectos políticos, sociales y económicos del desarrollo, lo que ha hecho que algunos especialistas en estos temas lo consideren un ejemplo de gradualismo exitoso. ${ }^{1}$ La calificación de "exitoso" —en el entorno regional, por cierto - no implica ignorar que, como todos los países latinoamericanos, Uruguay está hoy día profundamente afectado por los grandes problemas que se vinculan con la reestructuración productiva, el estrangulamiento del empleo y las presiones por desregular el mercado laboral. En rigor, las consecuencias de esos problemas ya se traducen en fisuras en el tejido social tradicionalmente integrado del país, así como en voces de alerta acerca de las dificultades para sustentar su estilo de crecimiento equilibrado.

\section{II}

\section{Uruguay en el contexto latinoamericano}

La mayoría de los estudiosos de problemas vinculados a la equidad coincide en que América Latina es la re-

$\square$ Las autoras agradecen a Carlos Filgueira, Juan Andrés Morães, Juan Carlos Veronelli, Rafael Diez de Medina y Alvaro Fuentes sus estimulantes sugerencias y sus comentarios a una versión preliminar de este trabajo. gión del mundo que ostenta las distribuciones más regresivas de la riqueza. Las cifras del Uruguay, sin embargo, lo separan claramente de su entorno regional (cuadro 1).

\footnotetext{
${ }^{1}$ Véase un análisis del caso uruguayo en profundidad y en perspectiva comparada en Filgueira y Morães (1999).
} 
CUADRO 1

América Latina (nueve países): Indices de desigualdad y pobreza

\begin{tabular}{|c|c|c|c|}
\hline & & Desigualdad $^{\mathrm{a}}$ & Pobreza ${ }^{b}$ \\
\hline \multirow[t]{3}{*}{ Argentina } & 1990 & 9.3 & 16 \\
\hline & 1997 & 9.6 & 13 \\
\hline & Variación & $3.2 \%$ & $-18.8 \%$ \\
\hline \multirow[t]{3}{*}{ Bolivia } & 1989 & 12.6 & 49 \\
\hline & 1997 & 10.8 & 47 \\
\hline & Variación & $-14.3 \%$ & $-4.1 \%$ \\
\hline \multirow[t]{3}{*}{ Brasil } & 1990 & 16.3 & 36 \\
\hline & 1996 & 16.8 & 25 \\
\hline & Variación & $3.1 \%$ & $-30.6 \%$ \\
\hline \multirow[t]{3}{*}{ Chile } & 1990 & 11.7 & 33 \\
\hline & 1996 & 11.8 & 19 \\
\hline & Variación & $0.9 \%$ & $-42.4 \%$ \\
\hline \multirow[t]{3}{*}{ Colombia } & 1990 & 10.2 & 35 \\
\hline & 1997 & 12.2 & 39 \\
\hline & Variación & $19.6 \%$ & $11.4 \%$ \\
\hline \multirow[t]{3}{*}{ Ecuador } & 1990 & 7.1 & 56 \\
\hline & 1997 & 7.4 & 50 \\
\hline & Variación & $4.2 \%$ & $-10.7 \%$ \\
\hline \multirow[t]{3}{*}{ México } & 1989 & 9.1 & 34 \\
\hline & 1996 & 7.7 & 38 \\
\hline & Variación & $-15.4 \%$ & $11.8 \%$ \\
\hline \multirow[t]{3}{*}{ Paraguay } & 1990 & 6.2 & 37 \\
\hline & 1996 & 7.6 & 34 \\
\hline & Variación & $22.6 \%$ & $-8.1 \%$ \\
\hline \multirow[t]{3}{*}{ Uruguay } & 1990 & 6.2 & 12 \\
\hline & 1997 & 4.7 & 6 \\
\hline & Variación & $-24.2 \%$ & $-50.0 \%$ \\
\hline
\end{tabular}

Fuente: CEPAL (1999).

a Cociente entre el ingreso medio del $10 \%$ más rico y del $40 \%$ más pobre.

b Porcentaje de hogares bajo la línea de pobreza.
En efecto, los valores de los índices de desigualdad y de pobreza para 1990 o para 1997 son menores en Uruguay que en los demás países que figuran en el cuadro. Asimismo, sus indicadores de cambio de la situación social en ese período registran una tasa de reducción de la pobreza y la desigualdad mayor incluso que la de Argentina y Chile, cuyos ritmos de crecimiento del producto bruto interno per cápita en esos años fueron más elevados que el de Uruguay (33.2\%, $53.3 \%$ y $27.2 \%$, respectivamente).

En suma, el país mostró más capacidad para amortiguar los efectos sociales negativos de los procesos de apertura y de ajuste macroeconómico que sus pares de la región.

El buen desempeño relativo de Uruguay en el campo de la justicia social tiene su correlato en la legitimidad que otorgan sus ciudadanos a la democracia y a sus instituciones, como muestra el cuadro 2. El compromiso de la población con el sistema democrático hace que la opinión pública uruguaya adjudique a este sistema mayor legitimidad, capacidad de respuesta, utilidad y responsabilidad que en la mayoría de los restantes países de la región. En cada una de las afirmaciones incluidas en dicho cuadro que indican confianza y satisfacción con el funcionamiento de la democracia, así como en la suma ponderada de los porcentajes de respuestas positivas a cada pregunta, los uruguayos manifiestan mayor conformidad y adhesión a las instituciones de la democracia que los residentes de otros países de la región. ${ }^{2}$

\begin{tabular}{|c|c|c|c|c|c|c|c|c|}
\hline & Argentina & Brasil & Chile & México & Paraguay & Perú & Uruguay & Venezuela \\
\hline La democracia es preferible a cualquier otra forma de gobierno & 82 & 48 & 54 & 57 & 58 & 58 & 86 & 64 \\
\hline Está satisfecho con el funcionamiento de la democracia en el país & 53 & 31 & 34 & 24 & 31 & 47 & 59 & 38 \\
\hline La democracia permite la solución de los problemas nacionales & 59 & 51 & 51 & 52 & 39 & 71 & 63 & 53 \\
\hline Las elecciones en el país son limpias & 78 & 26 & 82 & 52 & 39 & 64 & 83 & 19 \\
\hline $\begin{array}{l}\text { Los senadores y diputados se preocupan de lo que piensa la } \\
\text { gente como uno }\end{array}$ & 19 & 16 & 24 & 24 & 28 & 29 & 38 & 16 \\
\hline $\begin{array}{l}\text { La manera como uno vota puede hacer que las cosas sean } \\
\text { diferentes en el futuro }\end{array}$ & 75 & 53 & 56 & 53 & 62 & 75 & 77 & 52 \\
\hline Suma no ponderada & 366 & 225 & 301 & 223 & 228 & 344 & 406 & 242 \\
\hline
\end{tabular}

Fuente: Kaztman (1997), sobre la base a datos de Basañez, Lagos y Beltrán (1996).

${ }^{2}$ La predisposición democrática manifestada en estas respuestas no
resulta de patrones culturales que cristalizan de la noche a la maña-
na. Por el contrario, se ha gestado en el largo plazo. Sus rasgos van sedimentando a través de procesos que usualmente cubren varias generaciones y que tienen efectos inerciales profundos sobre las actitudes políticas de los ciudadanos. 
La justicia social y la adhesión democrática están estrechamente conectadas. La percepción de injusticias sociales o de desigualdad de oportunidades con otros grupos de la sociedad tiende a debilitar el compromiso de los afectados con las instituciones que hacen posible esas inequidades. A su vez, la falta de confianza en las instituciones torna "más complejos e inciertos los procesos de agregación de las preferencias de los individuos y mayores los conflictos de distribución de los recursos públicos. También es más difícil la integración económica y social de los diferentes grupos y es más factible que el aparato estatal quede sujeto a influencias de grupos de presión, corrupción e ineficiencia, todo lo cual contribuye a mantener la desigualdad" (BID,1998). En el gráfico 1 se muestra la asociación entre ambos fenómenos.
GRAFICO 1

Desigualdad y satisfacción con la democracia. 14 países latinoamericanos, 1996-1997

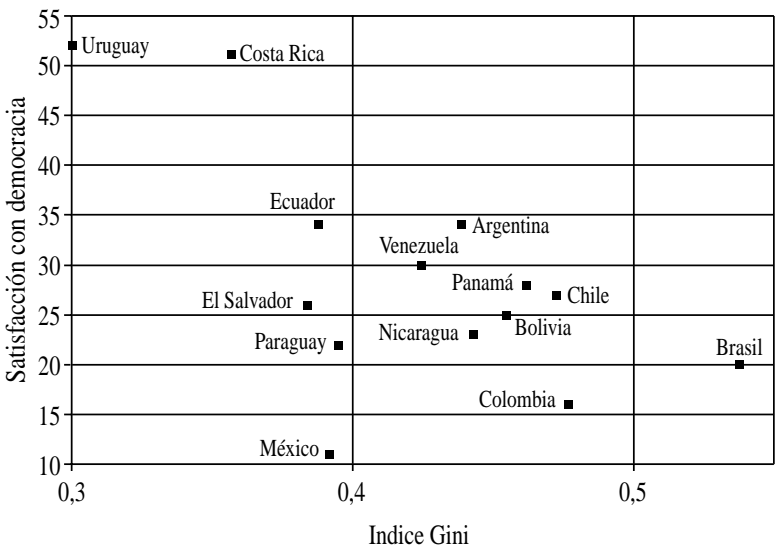

Fuente: Elaboración del autor sobre la base de CEPAL (1998) y Basañez y otros (1996).

\section{III}

\section{Tendencias de la pobreza y la desigualdad a partir de la restauración democrática}

\section{Pobreza}

La evolución general de la economía uruguaya permitió que en el período 1986-1997 el ingreso real medio de los hogares creciera más del $50 \%$. Ese crecimiento fue acompañado por una reducción significativa de la pobreza $^{3}$ en el Uruguay urbano (gráfico 2). De 1986 a 1998 el porcentaje de hogares pobres se redujo del $37 \%$ al $15.5 \%$, y el de hogares indigentes —esto es, con ingresos per cápita insuficientes para cubrir el costo de una canasta de alimentos-, tras un descenso inicial en los primeros años del período considerado, se mantuvo en un nivel aproximado al $1 \%$.

En el gráfico 3 se puede observar la relación inversa entre la evolución del ingreso nacional per cápita y la pobreza. En un país sin cambios abruptos en la distribución del ingreso, que además exhibe una con-

\footnotetext{
${ }^{3}$ El índice de pobreza utilizado aquí se basa en las estimaciones del costo de la canasta de consumo elaboradas por el Instituto Nacional de Estadística de Uruguay, basándose en los resultados de la Encuesta de Gastos e Ingresos de los Hogares realizada en 1994-1995. Aunque en general sigue la misma tendencia, este índice difiere en magnitud del utilizado con fines comparativos en el Panorama Social de América Latina (CEPAL, 1999), que fue la fuente del cuadro 1.
}

centración relativamente baja, no es de extrañar que los frutos del crecimiento se reflejen rápidamente en una reducción de la pobreza. Las curvas del gráfico reflejan también con claridad el "efecto tequila" de fines de 1994 y sus consecuencias inerciales, a las que se sumaron posteriormente las de las crisis que afectaron a Rusia y al sudeste asiático.

\section{GRAFICO 2 \\ Evolución de la pobreza Total urbano, 1986-1998 (Porcentajes)}

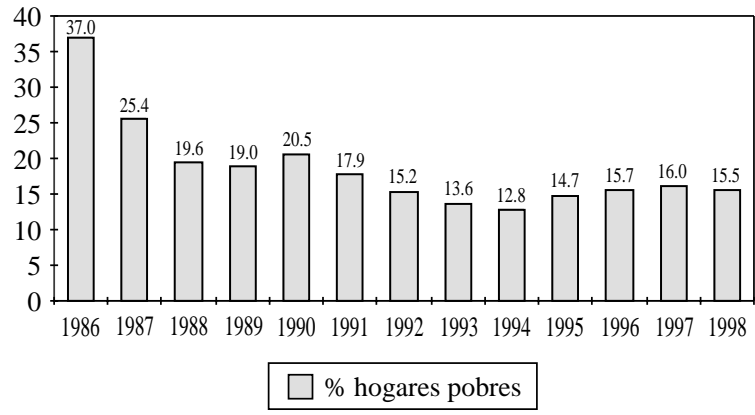

Fuente: Elaboración propia a base de las encuestas continuas de hogares, del INE. 
GRAFICO 3

Relación entre crecimiento y pobreza. Total urbano, 1986-1998

(Porcentajes)

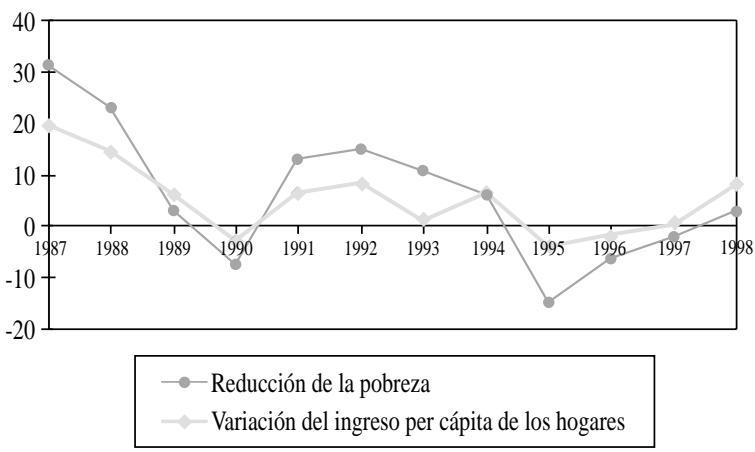

Fuente: Elaboración propia a base de las encuestas continuas de hogares, del INE.

Fuera de los vaivenes de la economía, quizás el factor singular más importante del descenso de la pobreza fue la enmienda constitucional aprobada por el plebiscito de 1989. Dicha enmienda estableció que los beneficios de los jubilados y pensionados se indexarían automáticamente de conformidad con el índice medio de salarios. Como cerca de la mitad de los hogares urbanos uruguayos (49.6\% en 1998) cuenta con algún ingreso proveniente de pensiones, el cambio significó que una importante proporción de los hogares pobres que incluían jubilados o pensionados dejaron de ser pobres. De hecho, entre 1989 y 1998 el porcentaje de hogares pobres que incluían al menos un jubilado o pensionado disminuyó de 40.2 a $32.4 \%$ con respecto al total de hogares pobres. Mirado desde otro ángulo, entre 1989 (año del plebiscito) y 1998, en los hogares urbanos la pobreza bajó un $18.4 \%$, en tanto que en aquellos que contaban con algún jubilado la reducción fue de $32.6 \%$ (gráfico 4 ).

Las estrategias familiares también hicieron su aporte a la reducción de la pobreza, principalmente a través de la incorporación de mujeres casadas a actividades remuneradas. La movilización de la fuerza de trabajo familiar dio lugar a un aumento de la proporción de miembros en el mercado de trabajo (densidad ocupacional) en los hogares de los primeros cinco deciles (gráfico 5). Lo inverso sucedió en hogares de mayores ingresos, en parte porque el alza de las pensiones permitió el traslado a los deciles más altos de hogares que incluían algún pensionado. Si bien la mayor densidad ocupacional amortigua los efectos de las crisis económicas, también tiene efectos negativos, particularmente en los hogares de menores recursos. Dado que en ellos se concentran los esfuerzos de re-
GRAFICO 4
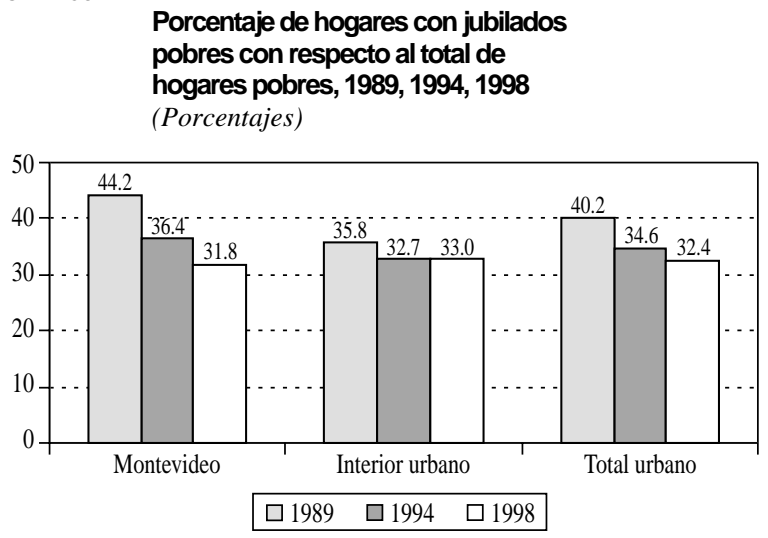

Fuente: Elaboración propia a base de las encuestas continuas de hogares, del INE.

GRAFICO 5

\section{Evolución de la densidad ocupacional. Total urbano, 1986-1998}

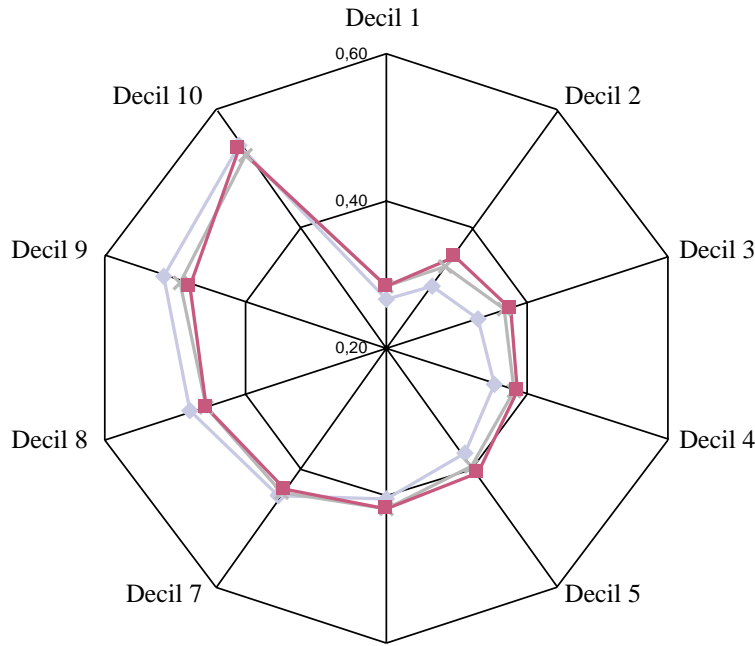

$\longrightarrow$ 1986-1990 1991-1994 - 1995-1998

Fuente: Elaboración propia a base de las encuestas continuas de hogares, del INE.

producción biológica y social de la población, el trabajo remunerado de la mujer casada restringe su capacidad de contribuir en lo que se refiere al cuidado y vigilancia de los hijos. Por otra parte, la incorporación temprana de éstos al mercado de trabajo disminuye significativamente sus oportunidades de acumular logros educativos (Filgueira, 1999).

Otros hogares se alejaron de la amenaza de la pobreza recurriendo a decisiones de limitar el tamaño de sus familias. De hecho, la fecundidad global en las áreas urbanas se redujo entre 1985 y 1996 de 2.89 a 
2.60 por mujer. En general, estas tendencias suelen reflejar el mayor capital humano incorporado por las mujeres y su decisión de utilizarlo mejorando sus oportunidades en el mercado de trabajo. Pero en este caso, la reducción también afectó a las categorías de mujeres con más probabilidad de caer en la pobreza. Las tasas para aquéllas sin instrucción bajaron de 3.92 a 2.88 , y para las que no terminaron la primaria, de 4.33 a 4.24. ${ }^{4}$ En suma, la mayor participación laboral de las mujeres casadas y la reducción del número de hijos contribuyeron a la reducción de la pobreza medida por los ingresos per cápita del hogar.

En los últimos quince años del siglo XX los cambios en el peso relativo de los hogares pobres fueron acompañados por significativos avances en la satisfacción de algunas necesidades básicas. Aunque no cubren todo el período, los datos que se presentan en el gráfico 6 muestran que entre 1991 y 1998 se registraron importantes avances en el acceso a energía eléctrica, a agua potable dentro de las viviendas, a cobertura médica y a mejores condiciones habitacionales.

\section{Desigualdad 5}

Como se mencionó al inicio de esta sección, la disminución de la pobreza y el mejoramiento de las condiciones de vida que se dieron en los últimos quince años del siglo XX pudieron haberse producido en distintos escenarios de distribución del ingreso. En Uruguay dicha distribución permaneció prácticamente invariable a lo largo del período (gráfico 7). En efecto, el índice de Gini de la distribución del ingreso per cápita (con valor locativo) entre hogares ${ }^{6}$ osciló alrededor de 0.41 , con una leve tendencia ascendente, sobre todo hacia fines del período. ${ }^{7}$

\footnotetext{
${ }^{4}$ Véase Instituto Nacional de la Familia y de la Mujer (por publicarse).

${ }^{5}$ El coeficiente de desigualdad utilizado (Gini) muestra diferencias en magnitud y en tendencia con el que se usa en el Panorama social de América Latina (CEPAL, 1999). Este último fue construido con una metodología que busca maximizar la confiabilidad de los resultados para definir la posición relativa de los países en la dimensión considerada y, por lo tanto, los criterios empleados deben ajustarse a las restricciones de las fuentes nacionales de información. Los resultados que se presentan en esta sección coinciden con los de otros estudios realizados para Uruguay (véase Vigorito, 1999, p. 259 , cuadro $2 \mathrm{~B}$ ).

${ }^{6} \mathrm{El}$ ingreso per cápita del hogar se calculó a partir de la agregación de los ingresos que llegan a él por concepto de remuneraciones del trabajo y del capital y pensiones, así como también los subsidios y transferencias y el valor locativo imputado por la propiedad de la vivienda. En dichos cálculos no se considera como integrante del hogar al servicio doméstico que vive en él.
}

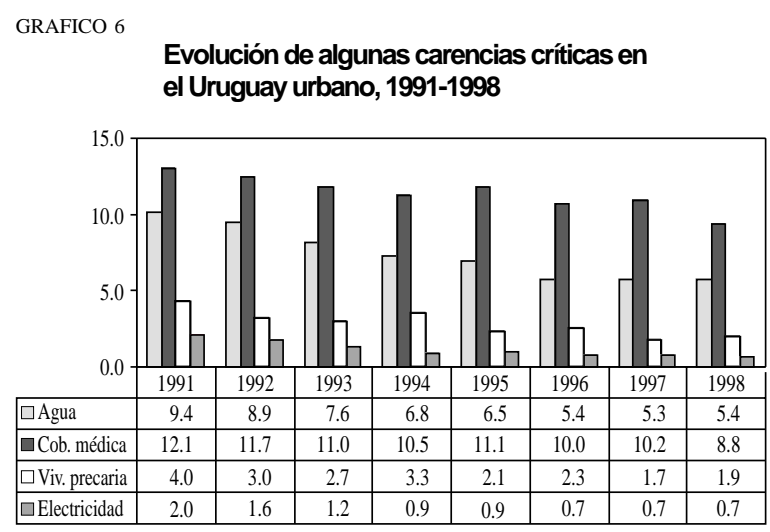

Fuente: Elaborado por el Informe de Desarrollo Humano de Uruguay (1999), a base de datos de las encuestas continuas de hogares del INE.

GRAFICO 7
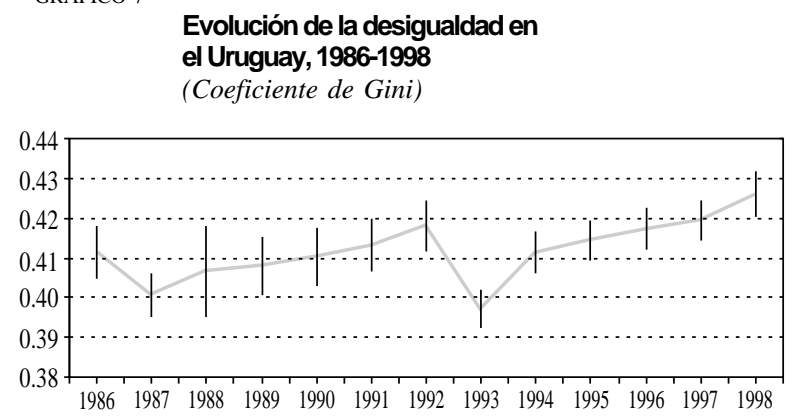

Fuente: Elaboración propia a base de las encuestas continuas de hogares efectuadas por el INE.

CUADRO 3

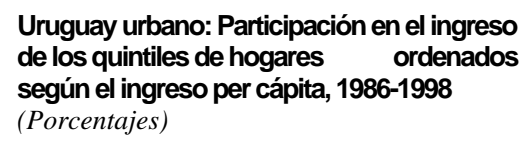

\begin{tabular}{lccccc}
\hline & Quintil 1 & Quintil 2 & Quintil 3 & Quintil 4 & Quintil 5 \\
\hline 1986 & 5.6 & 10.4 & 15.0 & 21.8 & 47.3 \\
1987 & 5.9 & 10.6 & 15.2 & 21.9 & 46.4 \\
1988 & 6.0 & 10.5 & 14.9 & 21.4 & 47.2 \\
1989 & 5.8 & 10.5 & 14.9 & 21.5 & 47.3 \\
1990 & 5.8 & 10.4 & 14.9 & 21.5 & 47.5 \\
1991 & 5.7 & 10.3 & 14.8 & 21.4 & 47.7 \\
1992 & 5.5 & 10.2 & 14.8 & 21.4 & 48.1 \\
1993 & 5.8 & 10.7 & 15.3 & 22.0 & 46.1 \\
1994 & 5.6 & 10.3 & 14.9 & 21.8 & 47.4 \\
1995 & 5.4 & 10.2 & 14.9 & 22.0 & 47.5 \\
1996 & 5.4 & 10.2 & 14.8 & 21.9 & 47.7 \\
1997 & 5.4 & 10.1 & 14.8 & 21.7 & 48.0 \\
1998 & 5.2 & 9.9 & 14.7 & 21.9 & 48.4 \\
\hline
\end{tabular}

Fuente: Elaboración propia sobre la base de las encuestas continuas de hogares efectuadas por el Instituto Nacional de Estadística (INE).

\footnotetext{
${ }^{7}$ Los valores del índice en los años noventa no son estadísticamente distintos a los de los ochenta, salvo en 1998. En ese año, el intervalo de confianza estadística de la estimación al $95 \%$ no se solapa con los correspondientes a los años ochenta.
} 
Un comportamiento similar se observa cuando en vez de utilizar una medida sintética como el índice de Gini se sigue la evolución de la parte del ingreso que afluye a los hogares ubicados en cada uno de los cinco quintiles de ingreso per cápita. Así, si bien los mo- vimientos a lo largo de todos los años del período 19861998 son de poca magnitud, se aprecia que pierde participación el $40 \%$ de hogares urbanos con menores ingresos, mientras la acrecienta el $20 \%$ de hogares más ricos (cuadro 3).

\section{IV}

\section{Factores determinantes de las tendencias en la distribución del ingreso}

\section{Consideraciones iniciales}

La escasa variación en los índices de distribución del ingreso puede ser engañosa, pues puede sugerir que los niveles de desigualdad son relativamente independientes tanto del tipo de crecimiento como de los grandes procesos económicos y sociales que afectan a las sociedades. ${ }^{8}$ La interpretación correcta va en otro sentido. Las sociedades están permanentemente expuestas a fuerzas que modelan sus estructuras en direcciones más o menos equitativas y que, por ende, afectan a diferentes categorías sociales con distinto signo e intensidad. Las categorías que se ven perjudicadas buscan contrarrestar esos efectos utilizando los recursos individuales y colectivos que puedan movilizar.

En este enfoque, los indicadores de distribución del ingreso (y de la riqueza cuando se dispone de información adecuada) se interpretan más bien como el resultado de una compleja trama de fuerzas que de un lado son activadas por el mercado y de otro por individuos, hogares y actores colectivos. Como veremos más adelante, los cambios en el mercado producen variaciones en la rentabilidad de los distintos factores de producción y afectan así tanto el promedio de ingresos como su distribución entre las distintas fuentes que los originan.

Los individuos reaccionan a los cambios en el mercado optando, en la medida de sus posibilidades, por distintas vías de acción. Dentro de sus hogares,

\footnotetext{
${ }^{8} \mathrm{Li}$, Squire y Zou (1998) examinaron las tendencias en la distribución del ingreso de 45 países sobre los cuales existía información de buena calidad para períodos prolongados. Encontraron que la mayoría (29) no mostraba tendencias distinguibles en una u otra dirección y que el resto se dividía igualmente entre las que aumentaban la desigualdad y las que la reducían
}

participan de las decisiones sobre el número de hijos, sobre mantenerlos o no en el sistema educativo cuando tal permanencia comienza a ser incompatible con las necesidades de ingreso, sobre la incorporación de personas al hogar o su separación de él, y sobre la frecuencia e intensidad de la participación laboral de cada uno de los miembros en edad activa. A su vez, a nivel institucional, los actores colectivos pugnan entre sí por una mayor incidencia en el diseño y la forma de aplicar los instrumentos de política, utilizando sus recursos sociales, políticos y económicos para aumentar o mantener su porción de los frutos del crecimiento o para minimizar su cuota del costo de las crisis. Todas estas fuerzas actúan bajo la superficie, dando forma a la distribución del ingreso y de la riqueza en la sociedad.

A continuación exploraremos, de manera muy sintética, algunos de los factores que podrían haber influido sobre la distribución del ingreso en Uruguay en los últimos quince años del segundo milenio.

\section{Factores determinantes}

\section{a) Apertura, ajuste fiscal y perturbaciones externas}

Aunque todavía es muy temprano para afirmar que los nuevos estilos de desarrollo han afectado la distribución del ingreso, algunos autores encuentran una asociación empírica entre los procesos de reformas estructurales que acompañan a esos estilos y una mayor desigualdad (Altimir, 1997). ${ }^{9}$ Todo intento de aplicar dicha hipótesis a Uruguay debería tomar en cuenta las características particulares de su proceso de reformas estructurales, entre otras, la ausencia de privatizaciones

\footnotetext{
${ }^{9}$ La afirmación de Altimir resulta del análisis de cinco países: Argentina, Brasil, Chile, Colombia y México.
} 
significativas y la temprana liberalización financiera que se realizó ya en los años setenta.

De todos modos, entre 1985 y 1998 Uruguay avanzó con fuerza en el proceso de apertura externa y en el control del déficit fiscal. Las barreras arancelarias se redujeron, pasando de un arancel medio de $40.7 \%$ a uno de $12.8 \%{ }^{10}$ (UNCTAD/CEPAL, 1998). En ese mismo período, el déficit fiscal global pasó de $6.3 \%$ a $1.0 \%$ del producto interno bruto (Presidencia de la República Oriental del Uruguay, Oficina de Planeamiento y Presupuesto, 1999) y la inflación se redujo de aproximadamente $70 \%$ a alrededor de $10 \%$.

Tanto la apertura externa como las políticas de reforma del Estado alteraron la composición del empleo. En muchos países de la región la globalización de sus economías trajo consigo un descenso del peso relativo de la industria en la absorción de trabajadores

${ }^{10}$ A partir de enero de 1998 el arancel subió tres puntos luego de un acuerdo de los países del Mercosur previo a la devaluación efectuada por Brasil, país que solicitó este aumento. y en el total del producto nacional. En Uruguay, que participó de estos procesos en el período considerado, los trabajadores industriales disminuyeron de $20.5 \%$ del total de trabajadores en 1986 a $16.3 \%$ en 1998. Esto es, casi un quinto de los trabajadores de la industria se trasladó a los servicios o alimentó la tasa de desempleo.

El ajuste fiscal fue acompañado de un achicamiento del aparato estatal. De trece países para los que se dispone de información comparativa entre el inicio de los años ochenta y fines de los noventa, doce, incluido Uruguay, vieron reducirse el porcentaje de trabajadores en empleos públicos (CEPAL, 1999). En ese período los empleados públicos que constituían aproximadamente un cuarto de la fuerza de trabajo urbana, pasaron a ser cerca de un sexto de ella, perdiendo así alrededor de $30 \%$ de su peso relativo.

Estas transformaciones no podían sino afectar la distribución del ingreso entre los hogares. De hecho, hasta que comenzaron a sentirse los efectos de la crisis mexicana, el ingreso medio de los hogares había crecido continuamente en el período (recuadro 1).

\section{Recuadro 1}

El mayor grado de apertura potenció los alcances de la crisis mexicana de fines de 1994, que se tradujo en un aumento del desempleo y de la pobreza. Mientras que las tasas de desempleo en Uruguay se mantuvieron alrededor del 9\% entre 1986 y 1994, a partir del "efecto tequila" se ubicaron entre el 11 y el 13\%. Las consecuencias de estas crisis económicas tienen cierta inercia que es estimulada, entre otras cosas, por una mayor cautela empresarial ante compromisos contractuales con nuevos trabajadores - actitud que se extiende aún a períodos de reactivación económica- y por una mayor inclinación a reemplazar mano de obra por equipamiento. Pero sus efectos también se traducen en más deserción escolar, a medida que miembros de la familia se vuelcan al mercado de trabajo para compensar la pérdida de ingreso de algunos de los miembros adultos, o en el retiro prematuro de la actividad de personas que quedan desempleadas a una edad en que las posibilidades de reingreso al mercado son muy bajas. En general, las situaciones de crisis obligan a los pobres a adoptar decisiones que tienen consecuencias de mediano y largo plazo sobre las posibilidades de los miembros del hogar de acumular los activos que su bienestar requiere.

Para evaluar el impacto de la crisis mexicana, hay que tener en cuenta que las diferencias de tamaño económico entre Uruguay y sus dos principales socios en el Mercosur hace que la incidencia indirecta del "efecto tequila" sobre Argentina y Brasil haya sido tanto o más importante que sus efectos directos sobre Uruguay. Es por eso que dicha crisis marcó un punto de inflexión en la estabilidad de los índices relativamente bajos de desigualdad y pobreza que caracterizaron la historia uruguaya en los últimos quince años del siglo XX. Como se ha señalado extensamente en los análisis realizados durante la década recesiva de los ochenta, los hogares de menores recursos son los primeros afectados en los períodos recesivos y los últimos en sacar ventajas de los períodos de auge económico, lo que produce una asincronía entre el ritmo de aumento y descenso de la pobreza conforme a las vicisitudes del crecimiento. La lectura de los datos sobre pobreza y desigualdad de los últimos años del siglo XX deberá también tomar en cuenta la acumulación de los efectos de las crisis posteriores a la mexicana (de Rusia, del sudeste asiático y de Brasil). 

por fuentes de ingreso, 1986-1998

\begin{tabular}{|c|c|c|c|c|c|c|c|c|}
\hline & \multicolumn{4}{|c|}{ Ingreso medio de los perceptores ${ }^{a}$} & \multicolumn{4}{|c|}{ Indice de Gini de los perceptores } \\
\hline & Trabajo $^{b}$ & $\begin{array}{l}\text { Jubilaciones } \\
\text { y pensiones }\end{array}$ & Capital $^{\mathrm{c}}$ & Total & Trabajo & $\begin{array}{l}\text { Jubilaciones } \\
\text { y pensiones }\end{array}$ & Capital & Total \\
\hline 1986 & 28.4 & 12.9 & 47.4 & 27.9 & 0.426 & 0.409 & 0.601 & 0.475 \\
\hline 1987 & 31.8 & 14.7 & 56.6 & 31.5 & 0.413 & 0.408 & 0.608 & 0.468 \\
\hline 1988 & 34.3 & 17.3 & 65.8 & 34.9 & 0.413 & 0.445 & 0.581 & 0.476 \\
\hline 1989 & 36.0 & 16.2 & 63.8 & 35.2 & 0.416 & 0.430 & 0.581 & 0.475 \\
\hline 1990 & 34.3 & 16.7 & 64.7 & 34.0 & 0.415 & 0.450 & 0.600 & 0.479 \\
\hline 1991 & 36.5 & 18.0 & 68.9 & 36.5 & 0.426 & 0.427 & 0.604 & 0.480 \\
\hline 1992 & 38.4 & 20.5 & 75.6 & 38.6 & 0.441 & 0.426 & 0.598 & 0.483 \\
\hline 1993 & 39.2 & 22.0 & 68.3 & 38.6 & 0.435 & 0.425 & 0.544 & 0.466 \\
\hline 1994 & 41.1 & 22.9 & 74.9 & 40.8 & 0.449 & 0.432 & 0.563 & 0.480 \\
\hline 1995 & 39.3 & 22.3 & 66.3 & 38.6 & 0.455 & 0.434 & 0.548 & 0.479 \\
\hline 1996 & 39.1 & 23.1 & 65.8 & 38.1 & 0.457 & 0.433 & 0.543 & 0.476 \\
\hline 1997 & 38.1 & 23.9 & 68.2 & 38.0 & 0.458 & 0.434 & 0.541 & 0.476 \\
\hline
\end{tabular}

Fuente: Elaboración propia basada en las encuestas continuas de hogares, del INE.

a Los ingresos medios por perceptor están expresados en precios de diciembre de 1995.

b Los ingresos del trabajo incluyen los salarios privados, públicos y de trabajadores por cuenta propia con o sin local.

c los ingresos del capital comprenden alquileres, intereses y los ingresos de los patrones (utilidades y remuneraciones).

d En 1998 hubo cambios en el relevamiento de la muestra de la encuesta continua de hogares (actualización del marco muestral, cambios en los criterios de reposición y eliminación de las localidades menores de 5000 habitantes) que pudieron significar saltos en los niveles de algunas variables que hasta el momento no han sido analizados.

Para interpretar correctamente las consecuencias de los procesos de apertura y ajuste fiscal sobre la equidad social es necesario rastrearlas mediante el análisis de los cambios producidos en las estructuras que median entre esos dos fenómenos, como la recomposición de las distintas fuentes de ingresos, las modificaciones en el mercado laboral y los instrumentos de política del Estado que se activan para contrarrestar eventuales efectos regresivos de esos procesos.

\section{b) Cambios en las fuentes de ingresos}

Entre 1986 y 1997 el país asistió a cambios en el peso relativo de las distintas fuentes de ingreso de los perceptores. El ingreso medio proveniente de jubilaciones y pensiones creció durante todo el período. El ingreso medio del capital se elevó hasta 1992 y luego cayó entre ese año y 1997 (cuadro 4). Finalmente, el ingreso medio del trabajo creció hasta 1994, pero a un ritmo menor que el de las otras dos fuentes y con una caída posterior que fue también más leve que la del ingreso del capital.

Por otro lado, la evolución de la distribución del ingreso difirió entre perceptores de ingresos de distintas fuentes. Los datos ilustran una tendencia concentradora del ingreso entre los trabajadores y, en los años noventa, también entre los pensionados; en cambio, se observa una desconcentración del ingreso entre los propietarios de capital (cuadro 4).

La estabilidad en la distribución de los ingresos totales entre los perceptores no implica necesariamente que haya una estabilidad similar en las tendencias de la desigualdad entre los hogares, ya que en definitiva éstas dependen de cómo se combinan los individuos en esos hogares.

Algunos trabajos han examinado el efecto de los cambios experimentados por las fuentes de ingresos sobre el grado de desigualdad total. Así, Vigorito (1999) analizó la contribución de cada fuente a la variación de la desigualdad entre 1986 y 1997 a partir de la descomposición del índice de entropía 1 (de Theil), ${ }^{11}$ que se mantuvo prácticamente estable (en 1986 ascendía a 32.85 y en 1997 a 33.05). La autora citada encontró que los salarios, las jubilaciones y pensiones y los ingresos de los trabajadores por cuenta propia contribuyeron en forma positiva a la evolución de la desigualdad en dicho período, en tanto que los ingresos de los patrones tuvieron un impacto

\footnotetext{
${ }^{11}$ Para ello utilizó la regla de descomposición de Shorrocks (1982 y 1983), retomada por Jenkins (1995) y Foster y Sen (1997) y la aplicó a la distribución del ingreso total del hogar (sin valor locativo) entre hogares.
} 
CUADRO 5

\section{Uruguay urbano: Contribución de las distintas fuentes de ingreso a la variación de la concentración del ingreso, 1986-1997}

Fuentes de ingreso (sin valor locativo)

Indice de Theil

Trabajo asalariado

2.79

Trabajo por cuenta propia

Ingresos de los patrones

Jubilaciones y pensiones

Otros ingresos

1.38

$-4.43$

1.22

$-0.76$

Total

0.20

Fuente: Vigorito (1999).

desconcentrador que prácticamente contrarrestó los movimientos de las otras fuentes (cuadro 5).

Estos resultados ponen de manifiesto que el peso relativo de las distintas fuentes de ingreso en Uruguay no permaneció inalterado, y que el impacto global de la evolución de estas fuentes sobre la desigualdad oculta cambios que se neutralizan entre sí.

Ahora bien, interesa conocer el influjo de las distintas fuentes de ingreso en el grado de desigualdad total. En Bucheli y Furtado (por publicarse) se cuantificó en qué medida dichas fuentes explican la evolución de la distribución del ingreso partiendo de una descomposición del índice de entropía $0 .{ }^{12}$ Se encontró que el componente de la desigualdad atribuible a las diferencias entre grupos de perceptores pasó de $9.4 \%$ en 1986 a $11.7 \%$ en 1992 , por lo que el leve incremento de la desigualdad entre 1986 y 1992 se debió fundamentalmente al aumento de las disparidades de ingresos entre las personas que los obtuvieron de fuentes distintas. En efecto, si bien todos los ingresos crecieron en dicho subperíodo, el alza de los ingresos asociados a la propiedad del capital fue de tal magnitud que despegó el extremo superior de la distribución.

\footnotetext{
${ }^{12}$ Se distinguen los dos componentes usuales: componente de desigualdad atribuible a las diferencias entre grupos y componente de desigualdad atribuible a las diferencias dentro de los grupos. Esta descomposición permite medir el poder explicativo de una clasificación: cuanto mayor sea la contribución porcentual de las diferencias entre grupos más potente será la clasificación realizada para explicar la desigualdad total. La clasificación contó con diez grupos caracterizados por personas en hogares cuyo ingreso provenía en más de $65 \%$ de una fuente claramente identificada — propiedad del capital, jubilaciones y pensiones y cuatro categorías ocupacionales del trabajo- y en los casos restantes de una combinación de distintas fuentes.
}

Posteriormente, de 1992 a 1997 las diferencias entre perceptores de ingresos de distintas fuentes tendieron a achicarse (cuadro 4). El ingreso medio de los jubilados y pensionados —que muestra los niveles más bajos- aumentó en esos años un 16.6\%; el del capital, ubicado en el otro extremo, cayó un 9.8\%, mientras que el ingreso medio del trabajo se mantuvo en sus niveles intermedios. Por lo tanto, el leve incremento del grado de desigualdad global a partir de 1992 se explicaría por comportamientos ajenos a la evolución de las fuentes, ya que el componente de la desigualdad entre grupos disminuyó (en 1997 sólo dio cuenta de $6.6 \%$ de la desigualdad) y aumentó la dispersión dentro de los grupos.

\section{c) Cambios en la rentabilidad de la educación}

El análisis de los cambios ocurridos en las fuentes mostró que el mayor aporte a la concentración del ingreso provino de los salarios y que a partir de 1992 aumentó la dispersión entre perceptores de ingresos del trabajo.

Esto llevó a examinar los cambios ocurridos en el mercado de trabajo. Se comprobó que el ingreso de los hogares cuyos jefes tenían educación terciaria creció por encima del de aquellos hogares cuyos jefes tenían sólo educación primaria. Esta evolución, que corresponde a grupos ubicados en el extremo superior e inferior de la distribución, tuvo un impacto concentrador que explicaría el leve incremento de la desigualdad hacia fines del período de estudio (Bucheli y Furtado, por publicarse).

En efecto, diversos estudios sobre Uruguay indican no sólo que la educación es el factor que más incide en la desigualdad de ingresos entre hogares, ${ }^{13}$ sino además que esa incidencia aumentó en los años noventa. Los resultados de esos trabajos, con magnitudes que varían según el índice y la clasificación utilizados, se presentan en el cuadro 6.

Apoya estos resultados la estimación de ecuaciones salariales para los trabajadores del sector privado en Uruguay, según la cual la rentabilidad marginal de los niveles educativos más altos creció hacia fines de los años noventa, agrandando las diferencias de salarios entre trabajadores con distinta educación (Bucheli y Furtado, 2000).

\footnotetext{
13 Varios trabajos indican que la influencia de otras variables es considerablemente menor: la edad del jefe de hogar y su condición de activo o pasivo explican cada una menos del $5 \%$ de la desigualdad total, en tanto que la región y la estructura del hogar lo hacen en alrededor del 10\% (Machado y Reggio, 1999; Vigorito 1999).
} 
CUADRO 6

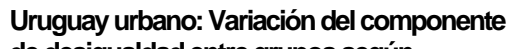
de desigualdad entre grupos según distintas clasificaciones por nivel educativo (Porcentajes)

\begin{tabular}{lccc}
\hline & 1986 & 1991 & 1997 \\
\hline $\begin{array}{l}\text { Bucheli y Furtado }^{\mathrm{a}} \\
\text { Indice de entropía 0 }^{\text {Vigorito b }}\end{array}$ & 18.2 & 20.5 & 21.3 \\
Indice de entropía 0 $_{\text {Indice de entropía 1 }}$ & 19.2 & 18.5 & 24.4 \\
Machado y Reggio c $_{\text {Indice de entropía 0 }}^{c}$ & 21.5 & 19.1 & 26.6 \\
Indice de entropía 1 & 24.1 & & \\
\hline
\end{tabular}

Fuente: Bucheli y Furtado (por publicarse); Vigorito (1999), Machado y Reggio (1999).

a La clasificación corresponde a la distinción por nivel educativo del jefe del hogar (0 a 6, 7 a 12, 13 o más años de educación) para las personas en hogares en que más del $65 \%$ del ingreso proviene del trabajo; para las personas dependientes del capital y de combinación de fuentes no se realizaron aperturas por nivel educativo. El grado de desigualdad se midió en la distribución del ingreso per cápita (sin valor locativo) entre personas.

b La clasificación distinguió entre hogares según el nivel educativo de su jefe: primer ciclo de secundaria, segundo ciclo de secundaria, UTU, Universidad, otros.

c La clasificación distinguió entre educación primaria incompleta, primaria completa, secundaria incompleta, secundaria completa, UTU, terciaria, otros. Se consideró la distribución del ingreso equivalente (con valor locativo) entre hogares.

\section{d) Transferencias}

Como se señaló en el apartado b), los cambios en el monto de las jubilaciones y pensiones también han hecho su aporte a la concentración del ingreso. Son varios los estudios que muestran que su indización desembocó básicamente en un traslado de perceptores de ingresos desde "sectores medios a más altos y en cambios en la composición demográfica de los deciles bajos" (Vigorito, 1997, p. 17; Bucheli y Rossi, 1994). $\mathrm{Al}$ respecto, cabe hacer notar que la media de ingresos por jubilaciones y pensiones experimentó un crecimiento mayor que el de cualquier otra fuente de ingreso en el período, y que también aumentó el índice de Gini en la distribución interna de los ingresos de este tipo en los años noventa (cuadro 4).

La concentración de jubilaciones y pensiones tendió a aumentar, contrariamente a lo sucedido con otras transferencias del Estado, como los beneficios sociales y los subsidios (cuadro 7). Como en el período 1988-1998 su participación en las transferencias totales del gobierno a los hogares urbanos creció del 74.8\% al $92.4 \%$, el resultado neto de las transferencias tuvo un efecto regresivo. Esto ocurrió pese a importantes cambios en algunos de los instrumentos, como las asignaciones familiares, que si bien tuvieron un claro efecto igualador, no lograron mitigar el efecto concentrador de las jubilaciones y pensiones, por lo que el esfuerzo realizado para focalizar los beneficios sociales y los subsidios no alcanzó a evitar que disminuyera la porción de las transferencias que llega a los más pobres (CEPAL, 1998). ${ }^{14}$

\section{e) Estrategias de los hogares}

Como se mencionó más atrás, para pasar de la distribución del ingreso entre perceptores a aquella entre hogares hay que tener en cuenta cómo se combinan los individuos en esos hogares. En efecto, pese a que en la práctica la distribución del ingreso entre los perceptores suele ser muy parecida a aquella entre los hogares, esto no siempre es así.

Los hogares cuentan con un margen de maniobra considerable para amortiguar los efectos de bajas en los ingresos de sus aportantes principales: pueden aumentar sus ingresos movilizando la fuerza de trabajo de que disponen y combinando distintas fuentes de ingreso; pueden tomar decisiones con respecto al tamaño de la unidad familiar, modificando sus planes sobre el número de hijos o postergando los embarazos, y pueden asociarse con otros miembros de la familia a fin de elevar el ingreso medio de los miembros.

Coincidiendo con una tendencia general en América Latina, la estrategia principal de los hogares uruguayos de menores ingresos fue la de elevar su densidad ocupacional (gráfico 4) mediante la participación de las mujeres casadas en el mercado laboral (CEPAL, 1998 y 1999). Al respecto, Vigorito (1999) comprobó que la incorporación de las mujeres al mercado de trabajo se tradujo en un aumento de su aporte a la generación de ingresos de los hogares (del 12\% en 1986 al $15.9 \%$ en 1997) y que a la vez su contribución a la desigualdad fue mayor puesto que sus ingresos de todas las fuentes mostraban una dispersión superior a la observada entre los hombres.

\footnotetext{
14 Aun cuando el aumento del monto de las jubilaciones y pensiones haya tenido un efecto regresivo, al hacer el balance de los cambios en la situación de bienestar de la población deberá tomarse en cuenta que, ante un mercado laboral crecientemente incierto, ellas contribuyen a la estabilidad de ingresos de los hogares. Esta mayor estabilidad beneficia no sólo a los jubilados y pensionados y a las personas que sin serlo conviven con al menos uno de ellos; también puede aliviar significativamente las preocupaciones por la subsistencia de sus padres entre quienes no comparten con ellos el mismo hogar.
} 
CUADRO 7 Uruguay urbano: Composición y distribución de las transferencias
del gobierno por quintiles de ingreso per cápita, 1988, 1991 y 1998

(Porcentajes)

Jubilaciones y pensiones $\quad$ Beneficios sociales Tubsidios $\quad$ Total transferencias

1988

$\begin{array}{lr}\text { Composición } & 74.8 \\ \text { Distribución } & \\ 1^{\mathrm{r}} \text { quintil } & 8.6 \\ 2^{\circ} \text { quintil } & 15.1 \\ 3^{\mathrm{r}} \text { quintil } & 18.2 \\ 4^{\circ} \text { quintil } & 21.6 \\ 5^{\circ} \text { quintil } & 36.4 \\ 6^{\circ} \text { quintil } & 100.0\end{array}$

Composición

Distribución

$1^{\mathrm{r}}$ quintil

$2^{\circ}$ quintil

$3^{\mathrm{r}}$ quintil

$4^{\circ}$ quintil

$5^{\circ}$ quintil

$6^{\circ}$ quintil

Composición

Distribución

$1^{\mathrm{r}}$ quintil

$2^{\circ}$ quintil

$3^{\mathrm{r}}$ quintil

$4^{\circ}$ quintil

$5^{\circ}$ quintil

$6^{\circ}$ quintil

Fuente: Elaboración propia basada en datos de las encuestas continuas de hogares, del INE.
$74.8+4.4$

$8.6 \quad 29.5$

25.3

18.2

$21.6 \quad 14.5$

11.2

100.0

1991

$\begin{array}{rr}20.8 & 100.0 \\ 16.7 & 11.2 \\ 17.4 & 16.0 \\ 18.2 & 18.3 \\ 20.1 & 21.0 \\ 27.6 & 33.5 \\ 100.0 & 100.0\end{array}$

100.0

100.0

$\begin{array}{rrr}29.2 & 19.3 & 10.4 \\ 21.5 & 16.3 & 15.2 \\ 20.7 & 16.0 & 18.9 \\ 14.5 & 13.0 & 21.7 \\ 14.0 & 35.4 & 33.7 \\ 100.0 & 100.0 & 100.0\end{array}$

1998
0.9

6.8

100.0

$\begin{array}{rr}6.2 & 37.7 \\ 12.5 & 26.6 \\ 17.0 & 17.2 \\ 23.1 & 13.1 \\ 41.1 & 5.4 \\ 100.0 & 100.0\end{array}$

23.2

7.7

13.3

17.4

22.6

39.1

100.0

\section{$\mathrm{V}$ \\ El marco político-institucional y las políticas públicas}

\section{Los procedimientos de reforma: gradualismo y secuencias con efectos no concentradores}

Uno de los aspectos esenciales de la evolución política y social uruguaya ha sido el proceso gradualista y ecléctico ${ }^{15}$ de sus transformaciones. Si se toma en cuen- ta la posición de Uruguay en el entorno regional, esta pauta, corroborada en el largo plazo, parece haber te-

\footnotetext{
15 Ecléctico, por cuanto se ha alejado en numerosas ocasiones del modelo ortodoxo de ajuste, o de lo que se ha dado en llamar el consenso de Washington.
} 
nido más virtudes que defectos. Se elige la expresión "parece haber tenido" ya que las argumentaciones que siguen, difíciles de someter a pruebas empíricas rigurosas, tienen un alto contenido especulativo.

Como el resto de los países de la región, Uruguay debió enfrentar el ocaso de un viejo modelo de desarrollo liderado por el Estado y orientado hacia adentro. Paralelamente, el país enfrentó la difícil reconversión a un modelo orientado a la exportación en el cual el mercado asume un papel central en la asignación de recursos y en el que destacan al menos cinco áreas claves de reforma: la liberalización financiera, la liberalización comercial, la reforma fiscal, las privatizaciones y reforma del aparato estatal, y la desregulación laboral.

El Banco Interamericano de Desarrollo (BID) elaboró un índice para medir el avance de estas cinco reformas en América Latina, cuya aplicación permite estimar la velocidad relativa de su aplicación en cada país (BID, 1997). Los datos pertinentes (gráfico 8) muestran que, entre uno y otro extremo del período 1985-1995, Uruguay registró una diferencia de $18 \%$ en los puntajes de avance de las políticas estructurales. Esa reducida diferencia - la menor entre los países para los cuales hay información disponible, incluyendo aquellos que como Chile y Colombia partieron en 1985 con puntajes similares al de Uruguay- hace de este último país un ejemplo de gradualismo en la región (BID, 1997, apéndice 5).

Además de las áreas de reforma utilizadas por el BID, debe considerarse la reforma social, en la cual Uruguay también ha sido gradualista y, como se verá más adelante, particularmente ecléctico.

El gradualismo que caracterizó a Uruguay tiene al menos dos méritos esenciales: favorece la defensa

GRAFICO 8

\section{Evolución del índice de políticas estructurales entre 1985 y 1995 $(1985=100)$}

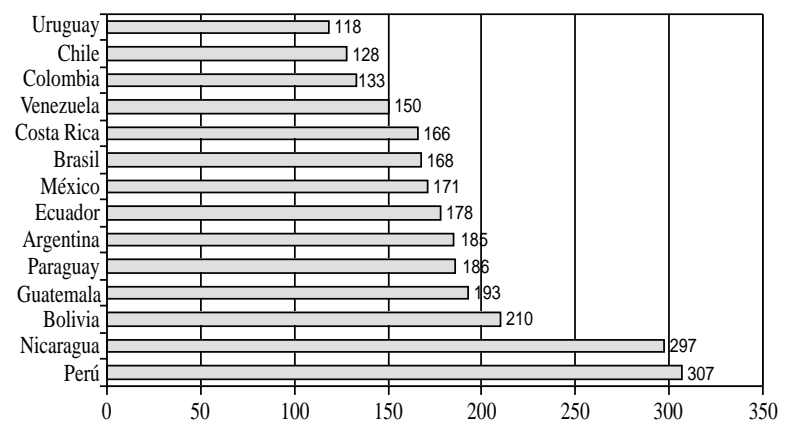

Fuente: Elaboración propia a base de BID (1997). de los intereses de los grupos subalternos y refuerza la democracia. Lo primero porque los recursos básicos de los sectores de menor poder - la movilización del número y la organización- son más eficaces en una negociación democrática y pierden gravitación ante políticas de choque o reformas abruptas.

El segundo mérito del gradualismo es que fortalece y reafirma la vigencia de mecanismos democráticos para la toma de decisiones difíciles en materia de modelos de desarrollo y ante problemas que son en definitiva distributivos. $\mathrm{O}$ para decirlo de modo negativo: las políticas de choque tienden a inhibir el desarrollo o la creación de culturas democráticas en las cuales la legitimidad de las decisiones descansa en los procedimientos y no en los resultados.

La secuencia de las reformas también presenta aspectos positivos en el país. Muy sintéticamente, puede afirmarse que el papel fundamental de las reformas es el de dejar en una especie de "intemperie competitiva" a actores que previamente operaban en "espacios protegidos y regulados". Dependiendo de la reforma que se aplique, ciertos actores estarán más a la "intemperie" que otros. A modo de ejemplo: mientras la rebaja arancelaria confronta a las empresas protegidas (es decir, al capital) con la competencia internacional, la desregulación laboral coloca al trabajo, más que al capital, ante el desafío de la competencia. En estas circunstancias, la secuencia de las reformas define el margen que tienen los actores afectados para trasladar costos a otros actores. A modo de ejemplo nuevamente: si las reformas arancelarias y la desregulación del mercado laboral se producen al mismo tiempo, las empresas podrán trasladar al sector asalariado buena parte de sus costos, disminuyendo salarios y beneficios y facilitando la reducción del personal con bajo costo para el empresario.

La secuencia reformista en Uruguay ha sido óptima en términos distributivos. En efecto, las primeras reformas que se han llevado a cabo han sido la financiera, la fiscal y la relativa al comercio exterior. Con excepción de la reforma fiscal, cuyo efecto sobre empresas y trabajadores no es claro, las otras dos afectan primordialmente al capital, forzándolo a absorber parte de los costos de reestructuración del modelo desarrollista. Si se considera que tanto la reforma laboral como la social han sido las más tardías, y que las privatizaciones han fracasado, la secuencia reformista aparece como particularmente progresiva. En efecto, han sido los asalariados y los sectores dependientes del Estado los que han perdido diversas formas de protección mas tardíamente, lo cual ha reducido el margen 
de los que concentran capital para trasladar costos a los sectores subalternos. La información ofrecida a lo largo de esta sección parece consistente con estas especulaciones. Como se señaló más atrás, la concentración de los ingresos del capital es la que muestra el descenso mayor en el período, ya que éste debe desenvolverse en entornos competitivos comunes, cuando antes extraía sus ventajas y ganancias de regímenes de protección estratificados.

\section{Los contenidos de la reforma: eclecticismo y límites al mercado}

Aun cuando tampoco en este punto resulta fácil someter el argumento a prueba empírica, parece razonable afirmar que el mantenimiento de la equidad en Uruguay estuvo relacionado con decisiones políticas no sólo en cuanto al ritmo y secuencia de las reformas, sino también a su contenido.

En una serie de trabajos que buscan comprender mejor el papel que han desempeñado la democracia - como sistema que permite a la población incorporar su voz y voto a las luchas distributivas- y el Estado - como garante y escudo de los más débiles para mejorar la distribución del bienestar-, Fernando Filgueira ha analizado de manera exhaustiva los mecanismos sociales y políticos que se movilizaron, las características específicas de los sectores y las estrategias de los grupos involucrados, en distintas instancias de reforma y de intentos de privatización de empresas públicas en Uruguay. ${ }^{16}$

Esos análisis muestran que la matriz sociopolítica uruguaya se ha mostrado reacia a incorporar el tipo de ajuste que se ha aplicado en la región. Al respecto cabe señalar lo siguiente:

i) En el período considerado la mayoría de las empresas y servicios públicos se mantuvieron en la esfera pública, salvo en el ámbito de la reforma de la seguridad social. Pero aun cuando el resultado de dicha reforma constituyó un claro alejamiento del viejo sistema, difiere significativamente de otros modelos de seguridad social como el chileno, pues se mantiene estatista y comprometido con fines distributivos que no tienen una presencia tan manifiesta en otras experiencias de reforma. ii) En el país se logró una notoria disminución del déficit público con cifras crecientes de gasto público social (gráfico 9). Una trayectoria diferente, que implicaba un proceso de ajuste estructural tendiente a disminuir este gasto, parece haber enfrentado numerosas dificultades en los últimos quince años del siglo XX. La trayectoria particular del Uruguay se ha sustentado fuertemente en un proceso político cuyas tramas de negociación y hallazgo de consensos tienden a señalar que el conjunto de reformas en la agenda de los gobiernos exige numerosos equilibrios. El principal de ellos es el mantenimiento de niveles elevados de gasto en aquellas políticas públicas que han caracterizado la formación y desarrollo de la sociedad y que han determinado en gran medida los avances que exhibe el país en cuanto a equidad social.

iii) No se modificó formalmente el funcionamiento del mercado laboral, pero sí hubo importantes modificaciones de facto que llevaron a una mayor precariedad del empleo. Más importante aún fue el cambio en las formas de negociación colectiva, que experimentaron una significativa descentralización.

iv) Hubo fuertes resistencias al desmantelamiento del sistema educativo. La reforma que se llevó a cabo en él se aparta mucho de aquellas orientadas al mercado, pues es decididamente estatista, universalista y fuertemente redistributiva.

La permanencia de los bienes públicos que sugieren los cuatro incisos anteriores preservó las condiciones que tradicionalmente han favorecido que la ciudadanía uruguaya exprese intensa y frecuentemente su "voz" como mecanismo correctivo, inhibiendo el ejercicio de la "salida" hacia las opciones de mercado. ${ }^{17}$

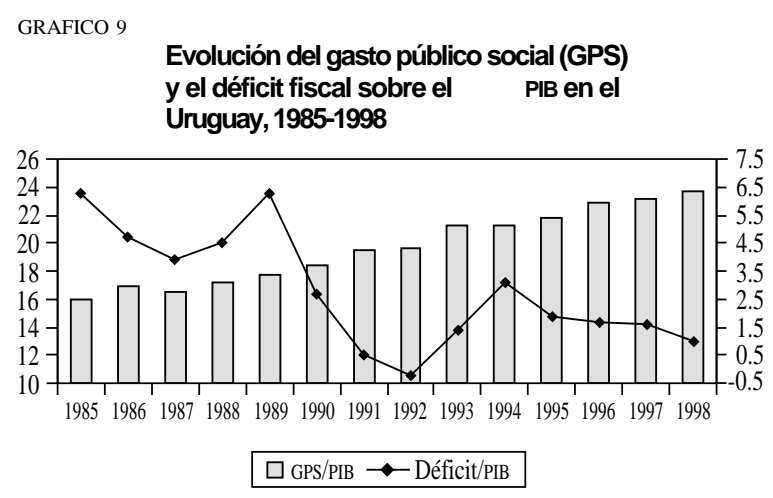
${ }^{17}$ Las nociones de "voz", "salida" y "lealtad" fueron desarrolladas
por Hirschman (1970).

16 Véase Filgueira y Morães (1999); Filgueira y Papadópulos (1997); Filgueira y Filgueira (1998). 


\section{Las claves sociopolíticas de una ruta reformis- ta gradual y ecléctica}

Como se dijo más atrás, las características peculiares de Uruguay en el contexto latinoamericano se tradujeron en una mayor capacidad para amortiguar las consecuencias negativas del nuevo estilo de crecimiento, principalmente por la aplicación selectiva de las reformas y el control del ritmo y la intensidad con que ellas se fueron incorporando. Veamos ahora someramente cuáles son las características centrales de la matriz sociopolítica uruguaya que ayudan a entender tanto el ritmo como los contenidos de sus reformas estructurales.

Pese a los importantes cambios económicos y sociales que experimentó el país entre 1970 y 1985, al finalizar este período seguían presentes en la estructura social uruguaya los actores centrales que habían participado del viejo modelo y que en buena medida se habían beneficiado de él. En efecto, los sindicatos que agrupaban a los trabajadores urbanos de la industria nacional, la propia industria protegida, los jubilados y pensionados al amparo del sistema de previsión social, así como el amplio sector de funcionarios públicos, eran todavía en 1985 los actores principales en las luchas distributivas del país: para llevar a cabo cualquier transformación era necesario negociar, articular e incorporar los intereses de estos actores en un contexto democrático recuperado. Allí reside tal vez una de las claves comparativas más importantes que diferencian, por ejemplo, a Uruguay de Chile. En este último país el grueso de las transformaciones estructurales se llevó a cabo bajo un régimen dictatorial, y en la matriz sociopolítica que la reconquistada democracia tuvo en sus manos quedaban ya pocas huellas y actores del viejo modelo de desarrollo. En Uruguay, por el contrario, la presencia de la vieja matriz y su transformación en un escenario democrático hizo que los eventuales perdedores en la transformación estructural pudieran negociar los costos que habrían de pagar y el tiempo para hacerlo.

Ahora bien, además de la matriz social anterior que se hizo presente a la hora de negociar los costos y beneficios de una transformación del modelo de desarrollo, había que agregar la matriz política necesaria para traducir demandas de actores en políticas concretas.

Políticamente, Uruguay ha sido y es el país con el proceso democrático más institucionalizado en América Latina, por dos rasgos sobresalientes de la dinámica política nacional: un sistema de partidos longevo y altamente institucionalizado y una arraigada cultura política de construcción de consensos. Estos dos factores han tenido un conjunto de efectos sobre el proceso político, en el cual la negociación entre partidos y los múltiples vínculos de éstos con los diversos agentes de la sociedad civil configuraron una trama plural en la modalidad de transacción entre los agentes decisores.

Por un lado, ambos factores condicionaron una relación particular entre los componentes técnicos de la elaboración de políticas y las elites partidarias, por la cual - a diferencia de otros países de América Latina- la vinculación entre técnicos y políticos estuvo absolutamente mediada por partidos políticos sólidos. Por otro lado, el sistema de partidos uruguayo ha sido capaz de procesar demandas articuladas como intereses generales en la provisión de bienes públicos, o como intereses particulares, principalmente en las respuestas a las presiones corporativas de la fuerza laboral sindicalizada y de los empresarios industriales.

La fuerte mediación política de la técnica y el saber especializado, así como la capacidad mediadora de los partidos en su sistema de respuestas a las demandas particulares y generales, configuraron en el largo plazo un sistema democrático marcado por la negociación permanente entre los actores políticos y sociales. ${ }^{18}$ Por ello, el elemento sorprendente del proceso uruguayo en el largo plazo estriba en su capacidad de construir transformaciones importantes en contextos de democracia y pluralismo (O'Donnell, 1993). Sumado a la pauta gradualista, un conjunto de características del marco institucional y del sistema político se han hecho presentes para imprimir a los contenidos de las reformas un sesgo marcadamente antiliberal, en donde si bien el papel del Estado como asignador de recursos se ve moderado, en ningún caso es sustituido por un sistema puro de mercado. Debe subrayarse que ello se da en un contexto internacional e interno que estimula fuertemente la adopción de un modelo de corte ortodoxo puro, pero que la matriz social y las estructuras políticas han mediado de modo eficaz en el procesamiento de esas presiones.

La experiencia uruguaya con las reformas estructurales indica que son los grados y modelos de incor-

\footnotetext{
${ }^{18}$ Ciertamente, esta observación de largo plazo se ha visto desfigurada por situaciones coyunturales de gran envergadura. En este sentido, el proceso autoritario (1973-1984) configuró un momento de notoria exclusión de la ciudadanía en términos políticos y sociales. Sin embargo, no logró revertir claramente la relación imperante entre técnicos y política, revelando que la estructura fue más fuerte que la coyuntura. Tampoco pudo revertir la pauta gradualista, a pesar de su capacidad discrecional para concretar reformas.
} 
poración de tales reformas, más que las presiones internacionales y las transformaciones productivas, los que determinan la tendencia de los países a implementar procesos de transformación neoliberal y de retracción de la protección del Estado. En otras palabras, las posibilidades de aplicar estos modelos de ajuste y transformación son directamente proporcionales a los grados históricos de exclusión sociopolítica de los sectores populares. En Uruguay se está en presencia de un Estado penetrado por las estructuras partidarias, un sistema partidario permeable a los sectores populares, y una sociedad que ha recibido en forma profusa protección y beneficios del Estado. Si bien, y como se ha destacado en este artículo, Uruguay efectuó importantes transformaciones en su modelo de desarrollo y en el papel que el Estado cumple en dicho modelo, la distribución de los costos y beneficios de tales transformaciones resultó notoriamente menos inequitativa que en sus pares latinoamericanos.

Tras las matrices sociales y políticas que el país presenta, hay una cultura política y social arraigada en un pasado que devuelve a un país sin grandes distancias sociales, políticas, étnicas y aún económicas: país de cercanías, como lo definiera Real de Azúa. Hay en él un acervo de altruismo y una baja tolerancia a las desigualdades extremas, atributos sin los cuales la matriz social y política del Uruguay hubiera resultado insuficiente para mantener, en un contexto internacional concentrador y desigualador, las identidades esenciales de una sociedad que se quiere igualitaria e integrada.

\section{VI}

\section{Reflexiones finales. Los desafíos a la equidad en el Uruguay del tercer milenio}

Dada la necesidad de reacomodamiento continuo frente a las turbulencias desatadas por la globalización, todo parece indicar que el tiempo necesario para que sedimenten economías nacionales viables será muy largo. Como se mencionó en la introducción, los expertos en el tema coinciden en que en el nuevo escenario los problemas centrales giran en torno al estrangulamiento del empleo y a las fuerzas que presionan por el repliegue de las conquistas laborales. Uruguay no escapa a las tendencias socialmente desestabilizadoras que se desencadenan en ese marco, lo que ciertamente plantea nuevos e importantes desafíos al mantenimiento de la equidad. ${ }^{19}$ En efecto, dado que se trata de diseñar y aplicar medidas que se ubican en el eje de las pugnas distributivas, enfrentar los nuevos problemas del em-

\footnotetext{
${ }^{19}$ Entre los elementos concentradores más importantes asociados a la globalización se halla la mayor rentabilidad de los factores que pueden traspasar las fronteras nacionales, como el capital y los recursos humanos de alta calificación. Las empresas grandes y en particular las empresas transnacionales, que hacen uso más intensivo de esos factores, mostrarán una creciente capacidad para aprovechar las economías de escala que genera la globalización tanto en el comercio como en el financiamiento de actividades productivas. A su vez, la ampliación de las posibilidades de relocalizar la producción reducirá la capacidad de negociación de los trabajadores e incrementará la inestabilidad de sus ingresos al hacerlos más sensibles a las perturbaciones de la demanda.
}

pleo remite a las áreas más "duras" de la política social (Kaztman y Gerstenfeld, 1990). La consecuente necesidad de articular intereses muy dispares pondrá a prueba las reservas de solidaridad de la sociedad uruguaya, así como la capacidad de sus instituciones para generar alrededor de estos temas la amplia base de apoyo político que sin duda se necesitará.

La preparación de Uruguay para hacer frente a esos desafíos y para mantener su posición de liderazgo regional en desarrollo social dependerá de la capacidad de su gente y la eficacia y eficiencia de sus instituciones, del umbral de tolerancia a la desigualdad en sus ciudadanos y de la predisposición de éstos a apoyar las correcciones necesarias cuando la desigualdad rebasa los umbrales tolerados. Se puede afirmar que el legado histórico uruguayo de justicia social y democracia, cristalizado en sus estructuras básicas (mercado, propiedad, Estado, etc.) ha determinado las condiciones de vida y las actitudes de su población, generando en ella una baja tolerancia a la desigualdad y una importante reserva de altruismo y solidaridad. ${ }^{20}$ Los comportamientos orientados por estos valores se ma-

\footnotetext{
${ }^{20}$ Véase el tratamiento de la noción de acervo de altruismo en Paci (1988).
} 
nifiestan en el apoyo a los mecanismos político-institucionales que se activan en defensa de los más débiles. ${ }^{21}$

Las actitudes solidarias se sustentan también, al menos, en una capacidad de empatía que permite colocarse en el lugar de otros y comprender la mayor o menor gravedad de sus problemas, y en un sentimiento de obligación moral que inclina al que lo posee a actuar en beneficio de los demás.

Estos sentimientos, capacidades y actitudes se actualizan y refuerzan cotidianamente a través del contacto informal, cara a cara, entre personas de distinto origen social en espacios no constreñidos por las jerarquías propias de las relaciones de mercado. Los sentimientos serán más fuertes cuanto más intensos y frecuentes sean los contactos. Por el contrario, todos los procesos que llevan a reducir las oportunidades de contacto informal entre las clases sociales tienden a debilitar los sentimientos de solidaridad y a elevar el umbral de tolerancia a la desigualdad.

La literatura que trata estos temas ha identificado diversos procesos que disminuyen la probabilidad de esos contactos informales entre clases. Los más importantes se dan en el ámbito residencial, en el ámbito de los servicios básicos y en el ámbito de lugares de tránsito, compras o esparcimiento.

En el primero de estos ámbitos, la segregación residencial lleva a concentrar en los mismos vecindarios a personas con niveles socioeconómicos similares. Las formas extremas de esta segregación son los guetos pobres y los guetos ricos. En las grandes ciudades latinoamericanas ya se observan barrios que congregan a sectores medios de características homogéneas. A la polarización espacial de las clases sociales en el medio urbano se está sumando la aparición de los llamados "enclaves fortificados", núcleos habitacionales que se aíslan de su entorno geográfico inmediato mediante barreras físicas y sofisticadas tecnologías de seguridad; como contrapartida, algunos guetos pobres también erigen barreras al ingreso de representantes de la sociedad que funciona fuera de sus fronteras. Si bien estos procesos son embrionarios en Uruguay, un estudio reciente muestra que entre 1985 y 1995 aumentó la homogeneidad de la composición social dentro de cada barrio y, por lo tanto, se acentuó la heterogeneidad entre barrios.

\footnotetext{
${ }^{21}$ Otro conjunto de motivaciones que puede desencadenar ese apoyo no nace ya de la aversión a la desigualdad, sino del temor a las externalidades de la inequidad social: la inestabilidad política, el debilitamiento de la legitimidad de las instituciones y la consecuente dificultad para movilizar la opinión pública en apoyo a proyectos de cambio, ante la inseguridad pública, etc.
}

En el segundo, la segmentación de los servicios básicos se suma a los fenómenos que socavan el acervo de solidaridad de un país. Por su crucial importancia para el aprovechamiento de las oportunidades de movilidad social, la segmentación educativa ha recibido una especial atención. La deserción de la educación pública por sectores medios priva a ésta de una "voz" en la lucha por mantener su calidad, al mismo tiempo que desestimula a esos sectores a pagar altos impuestos con ese propósito, ${ }^{22}$ pero también priva a los niños de menos recursos de contactos que facilitan la incorporación de actitudes y aspiraciones de clase media (por ejemplo, el convencimiento de que los esfuerzos de aprendizaje se recompensan con logros y que por lo tanto es conveniente diferir gratificaciones inmediatas e invertir en la acumulación de recursos humanos en el largo plazo). En los últimos años ha habido procesos embrionarios de segmentación educativa en Montevideo (no así en el interior urbano del país) por los cuales una proporción creciente de niños y jóvenes de los deciles de ingreso más altos concurre hoy a establecimientos privados, mientras la gran mayoría asiste a establecimientos públicos gratuitos (Kaztman, 1997); afortunadamente, estas tendencias están siendo contrapesadas por una ambiciosa reforma educativa dirigida a elevar la cobertura y la calidad de la enseñanza pública. Consideraciones similares podrían hacerse con respecto a la segmentación de otros servicios básicos, como la salud y, más recientemente, la seguridad pública. ${ }^{23}$

El tercer ámbito de encuentros informales entre las clases que podría verse afectado por la deserción de las clases medias está constituido por los lugares de tránsito, de compras y de recreación y esparcimiento, e incluye espacios tan variados como los bares, los pequeños negocios de barrio, las playas y los espectáculos populares como el fútbol y las fiestas de carnaval.

Con la distinción entre estos tres ámbitos se pretende poner de relieve la variedad de caminos por los cuales es posible promover la sociabilidad pluriclasista y contrarrestar las poderosas tendencias a la privatización y al aislamiento de las clases.

\footnotetext{
22 Como argumenta Barry, la conformidad con altos impuestos permite elevar la calidad de las prestaciones colectivas y a la vez reduce en los grupos de mayores ingresos los recursos disponibles para invertir en la adquisición privada de servicios, todo lo cual desalienta la deserción de los espacios públicos (Barry, 1998, p. 23).

${ }^{23}$ El automóvil, quizás el símbolo por excelencia de la movilidad social, aleja crecientemente a las clases medias de las adversidades y contingencias del transporte público y de la sociabilidad informal que tales situaciones suelen estimular.
} 
Cuando los procesos de segregación y segmentación confluyen en los tres ámbitos señalados, hay porciones de la sociedad que comienzan a quedar involuntariamente al margen de los sectores que representan el comportamiento modal de la sociedad. Ese aislamiento nutre la consolidación de subculturas marginales, la exclusión social y los mecanismos de reproducción intergeneracional de la pobreza.

La lentitud con que se va dando el decaimiento de los espacios pluriclasistas de sociabilidad informal en las ciudades hace que sus consecuencias sobre la integración social pasen generalmente inadvertidas para las mayorías ciudadanas. Por ende, esos espacios son usualmente subestimados como factores de integración y como fuentes de renovación de las reservas de altruismo, solidaridad y aversión a la desigualdad. Sin embargo, los efectos de su deterioro irrumpen tarde o temprano, a veces en forma violenta, anómica e inesperada, a través de los correlatos socialmente disruptivos de una pobreza marginada por la concentración de privaciones y por un progresivo aislamiento de las pautas modales de la sociedad. La respuesta de las clases medias es apartarse de los lugares y servicios públicos ocupados por las "clases peligrosas", cuyos comportamientos, cultivados en el aislamiento y la precariedad generalizada, aparecen ante las otras clases como exóticos y desviados. La deserción de las clases medias no hace más que acentuar el decaimiento de los espacios públicos, estrechando de ese modo el campo de experiencias que estimulan la capacidad de empatía con los sectores menos favorecidos y los sentimientos de obligación moral hacia ellos, y elevando, por ende, el umbral de tolerancia a la desigualdad.
El objetivo de fortalecer la integración social en las ciudades a través de la promoción de los espacios públicos pluriclasistas puede parecer alejado de las posibilidades de las políticas estatales, en parte porque los recursos que habría que destinar tal vez competirían con los requeridos por otras prioridades en la agenda social vinculadas al alivio de la pobreza. Ciertamente esa percepción se ajusta a la realidad de muchas de las grandes ciudades de la región donde la segregación residencial, la segmentación de los servicios y la deserción de las clases medias de los lugares públicos de sociabilidad informal pluriclasista están tan avanzadas, que las posibilidades de frenarlas o revertirlas a corto o mediano plazo parecen carentes de realismo. Pero este no es el caso de Uruguay, donde estos procesos son embrionarios y las grandes mayorías de la sociedad no parecen dispuestas a dejar que los bienes públicos se deterioren, máxime si se gana conciencia de que ese deterioro también implica el debilitamiento de un legado de justicia social y democracia que se asume como una dimensión destacada de la identidad nacional.

Por otra parte, son muchas las iniciativas de integración social en las ciudades de América del Norte y Europa - específicas para ese fin o presentes en la elaboración de políticas sectoriales- que tienen que ver con las medidas de ordenamiento urbano, la selección de beneficiarios de conjuntos habitacionales subsidiados, la defensa de la calidad de los servicios públicos y la promoción de espacios urbanos que estimulen los contactos informales entre las clases. Del amplio espectro de iniciativas de integración social urbana que han probado ser exitosas, se pueden aprovechar las que se ajustan más a los recursos y a las características singulares de la sociedad uruguaya.
Altimir, O. (1997): Desigualdad, empleo y pobreza en América Latina: efectos del ajuste y del cambio en el estilo de desarrollo, Desarrollo Económico, vol 37, N 145 , Buenos Aires, Instituto de Desarrollo Económico y Social (IDES).

Barry, B. (1998): Social Exclusion, Social Isolation and Distribution of Income, Case paper, $\mathrm{N}^{\circ} 12$, Londres, London School of Economics.

Basañez, M., M. Lagos, y T. Beltrán (1996): Reporte 1995: encuesta Latinobarómetro, Santiago de Chile.

BID (Banco Interamericano de Desarrollo ) (1997): América Latina tras una década de reformas, Progreso económico y social en América Latina. Informe 1997, Washington, D.C.

(1998): América Latina frente a la desigualdad, Progreso económico y social en América Latin. Informe 1989-1999, Washington, D.C.

Bucheli, M. y M. Furtado (por publicarse): La contribución de las distintas fuentes de ingreso a la evolución de la desigualdad en el Uruguay urbano 1986-1997, Montevideo, Oficina de la CEPAL en Montevideo.
(2000): La evolución de la participación de las fuentes de ingreso en Uruguay (1986-1997), trabajo presentado al Seminario de Economía Social, Montevideo, Universidad de la República, Departamento de Economía, marzo.

Bucheli M. y M. Rossi (1994): La distribución del ingreso en Uruguay 1948-1992, Documento $\mathrm{N}^{\circ} 10$, Montevideo, Universidad de la República, Departamento de Economía.

Bucheli, M.(1997): Equidad en las asignaciones familiares de Uruguay, Montevideo, Oficina de la CEPAL en Montevideo.

CEPAL (Comisión Económica para América Latina y el Caribe) (1998): Panorama social de América Latina, 1997, Santiago de Chile.

(1999): Panorama social de América Latina, 1998, Santiago de Chile.

Filgueira, C. (1999): Vulnerabilidad, activos y recursos de los hogares: una exploración de indicadores, en R. Kaztman (coord.), Activos y estructuras de oportunidades: estudios sobre las raíces de la vulnerabilidad social en Uruguay, Montevideo, Oficina de la CEPAL en Montevideo. 
Filgueira, C. y F. Filgueira (1998): Taming market reform: The politics of social state reform in Uruguay, Montevideo.

Filgueira, F. y J.A. Morães (1999): Political Environments, Sector Specific Configurations and Strategic Devices: Understanding Institutional Reform in Uruguay, IDB, working paper series $\mathrm{N}^{\circ} \mathrm{R}-351$, Washington, D.C., Banco Interamericano de Desarrollo (BID).

Filgueira, F. y J. Papadópulos (1997): Putting conservatism to good use? Long crisis and vetoed alternatives in Uruguay, en D.A. Chalmers y otros, eds., The New Polítics of Inequality in Latin America, Oxford, Reino Unido, Oxford University Press.

Foster, J. y A. Sen (1997): On Economic Inequality after Quarter Century, Oxford, Reino Unido, Clarendon Press.

Hirschman, A.O. (1970): Exit, Voice and Loyalty: Responses to Decline in Firms, Organizations and States, Cambridge, Massachusetts, Harvard University Press.

Instituto Nacional de la Familia y de la Mujer (por publicarse), Mujer y estadísticas, Montevideo.

Jenkins, A. (1995): Accounting for inequality trends: Decomposition for the UK, 1971-1986, Economica, $\mathrm{N}^{\circ} 62$, Londres

Kaztman, R. (1999): Activos y estructuras de oportunidades; estudios sobre las raíces de la vulnerabilidad social en Uruguay. Montevideo, Oficina de la CEPAL en Montevideo. (1997): Marginalidad e integración social en Uruguay, $R e$ vista de la CEPAL, $\mathrm{N}^{\circ}$ 62, LC/G.1969-P, Santiago de Chile, CEPAL.

Kaztman, R. y P. Gerstenfeld (1990): Areas duras y áreas blandas en el desarrollo social, Revista de la CEPAL, N 41, LC/G.1631-P, Santiago de Chile, CEPAL.

Li, H., L. Squire, L. y H.F. Zou (1998): Explaining international and intertemporal variations in income inequality, The Economic Journal, vol. 108, $\mathrm{N}^{\circ} 446$, Oxford, Reino Unido, Blackwell Publishers.
Machado, A. e I. Reggio (1999): Incidencia de la reforma en el mecanismo de ajuste de las pasividades de 1990 sobre la distribución del ingreso de los hogares. Uruguay: 1986-1997, Montevideo, Universidad de la República, monografía para optar al grado de Licenciado en Economía.

O’Donnell, G. (1993): Acerca del Estado, la democratización y algunos problemas conceptuales: una perspectiva latinoamericana con referencia a países poscomunistas, Desarrollo económico, vol. 33, $\mathrm{N}^{\circ} 130$, Buenos Aires, Instituto de Desarrollo Económico y Social (IDES).

Paci, M. (1998): Il welfare state come probleme di egemonia, Stato e mercato, $\mathrm{N}^{\circ} 22$, Roma, abril.

Presidencia de la República Oriental del Uruguay, Oficina de Planeamiento y Presupuesto (1999): Datos económicos y sociales del Uruguay, Montevideo.

PNUD (Programa de las Naciones Unidas para el Desarrollo), Oficina de Uruguay (en prensa): Informe de desarrollo humano de Uruguay, Montevideo.

Shorrocks, A. (1982): Inequality decomposition by factor components, Econometrica, vol. 50, Evanston, Illinois, Econometric Society.

(1983): The impact of income components on the distribution of family income, Quarterly Jounal of Economics, vol. 98, Cambridge, Massachusetts, Harvard University.

UNCTAD/CEPAL (1998): Política comercial a nivel país y los acuerdos de la Ronda Uruguay, Montevideo, enero.

Vigorito, A. (1997): Una distribución del ingreso estable. El caso de Uruguay 1986-1997, Montevideo, Universidad de la República, Instituto de Economía.

(1999): La distribución del ingreso en Uruguay entre 1986 y 1997, Revista de economía, vol. 6, N² 2, Montevideo, Banco Central del Uruguay. 